\title{
Impact of Educational Intervention on Knowledge Regarding HIV/AIDS among Adults
}

\author{
Sharma $M^{1}$ \\ ${ }^{1}$ TUIOM Nursing Campus, Maharajgunj, Kathmandu.
}

\begin{abstract}
Background: HIV/AIDS is the genuine public health problem; in which prevention is the mainstay of the response where adult can play principle role in the society. The study aimed at finding out the effectiveness of the education intervention in improving knowledge among adults regarding the HIV/AIDS.

Methods: A pre- experimental semi structured interview was conducted to measure research variables among a group of 67 adults, who were the members of Local Community Organizations (LCOs) of BagashoriVDC of Bhaktapur in pre- test and post test. The obtained data was analyzed by using descriptive and inferential statistics.

Results: The findings revealed that after intervention respondents had significantly higher $(\mathrm{p}=0.001)$ mean knowledge about HIV/AIDS.

Conclusion: The test confirmed that the education program on HIV/AIDS was able to considerably improve people's knowledge about HIV/AIDS.

Key words: adults, educational intervention, knowledge, HIV/AIDS
\end{abstract}

\section{INTRODUCTION}

After 25 years later since its discovery in 1981, 40.3 million people worldwide are living with HIV and 3.1 million people died by AIDS and is capable of "hollowing out" the every core of a society, destroying the often most economically productive age group (25 to 45 years). ${ }^{1}$ High risk groups within South Asian countries are showing evidence of dangerously high prevalence rates of HIV in the ranges of $60 \%$ to $70 \%{ }^{2}$

South East Asia Region has the second largest number of people living with HIV/AIDS, next only to Sub-Sahara Africa Nepal is a highly diversified country in terms of geography, ethnicity, language, and culture, where the topography, environmental degradation, poverty and economic migration are all linked to HIV. ${ }^{3}$ Since HIV infection is noted in all regions of the country, the highest prevalence rates found in the Central Region. ${ }^{4}$

In 1988 when the first case of HIV/AIDS was diagnosed, Ministry of Health and Population (MoHP) and Department of Health Science (DoHS) and other stakeholders came forward to address HIV and AIDS issues by preventive aspects.

This study aimed at finding out the effectiveness of the education intervention in improving knowledge about

Correspondence: Muna Sharma, TUIOM Nursing Campus, Maharajgunj, Kathmandu, Nepal. Email: munasharma2006@yahoo.com 
HIV/AIDS among adults by; determining the knowledge before and after education intervention and finding out the difference between the pre-test and post-test knowledge about HIV/AIDS among the adults.

\section{METHODS}

The design of the study was pre- experimental, where Pre- test, intervention and post test method were used to identify the impact of education intervention on knowledge about HIV/AIDS among the adults (male and female of age group between 20 to 50 years). A group of 67 adults were drawn from all 25 local community organizations (LCOs) of Bagashori VDC in Bhaktapur district, who were the members and were participated in the chairman- manager conference. Those organizations which were formed by the local people of Bagashori VDC in their own initiation with the help of local development fund (LDF), district development committee (DDC) Bhaktapur, in each ward, were considered as LCOs.

In order to measure the research variables a semi structured interview questionnaire was developed and was translated to Nepali.

The content validity of the instrument was established by literature review, consultant of HIV/AIDS, research advisor and subject teachers. The reliability of the instrument was established by pre testing the instrument on 7 adults who were the LCOs members of Dadhikot VDC of Bhaktapur district. On the basis of feedback, Questionnaire number 3.1 (a, d and e) of the Nepali version instrument was modified to make the language simple. The respondents were interviewed only by the Investigator.

An educational package was developed by the researcher with the help of literature available on HIV/AIDS. This consisted of meaning about HIV/AIDS, nature of disease, high risk groups, mode of transmission symptoms of AIDS, availability of drug, and preventive aspects of HIV/AIDS. Package was also translated in Nepali language.

Written permission to conduct the study was obtained from the authorities of the selected district. Informed consent was obtained from the subjects prior the interview. Identification number was used during pre and post interview. After pre-testing one and half hour teaching session was conducted for the same 67 respondents who had participated in the pre-test. The method used for teaching was lecture combined with active group participation. Educational materials used in intervention were; brochers, pamphlets and training materials. The educational intervention was carried out in two sessions at the convenience of the subjects of the study. After 1 and $1 / 2$ weeks following intervention post-test was undertaken by using the same interview questionnaire that was used in the pre-test. All 67 respondents participated in the post-test.

Both descriptive and inferential statistics were applied to show the significant difference of pre-test and posttest knowledge about HIV/AIDS.

\section{RESULTS}

Total $40.3 \%$ of respondents were literate followed by 25.4 were illiterate (Table 1). Farming was the occupation of $40.2 \%$ of respondents followed by $10.5 \%$ each were service and business. Female were the principal participants of the study, which accounted $92.5 \%$ followed by $7.5 \%$ male. Most of the respondents (79.1\%) were married and only one $(1.4 \%)$ respondent was widow.

\section{Table 1. Respondents' Demographic Characteristics}

\begin{tabular}{|lcc|}
\hline $\begin{array}{l}\text { Demographic } \\
\text { Characteristics }\end{array}$ & Number=67 & percentage \\
\hline Education Level & & \\
Illiterate & 17 & 25.4 \\
Literate & 27 & 40.3 \\
10+2 and higher & 23 & 34.3 \\
Marital Status & & \\
Unmarried & 13 & 19.4 \\
Married & 53 & 79.1 \\
Widow & 1 & 1.4 \\
Occupation & & \\
Farmer & 27 & 40.2 \\
Housewife & 26 & 38.8 \\
Service & 7 & 10.5 \\
Business & 7 & 10.5 \\
Ethnicity & & \\
Brahmin & 35 & 52.2 \\
Chhetri & 27 & 40.2 \\
Newer & 3 & 4.4 \\
Disadvantage & 2 & 2.9 \\
Gender & 52.5 \\
Male & 5 & \\
Female & & \\
\hline
\end{tabular}

In the pre-test most of the people meant HIV/AIDS was blood borne disease and in the post-test majority said HIV/AIDS is sexually transmitted and blood borne disease as well (Table 2). The mean score on knowledge about the meaning of HIV/AIDS was 1.3 in the pre-test and 2.4 in the post-test while standard deviation was 0.67 in the pre-test and 0.50 in the post-test respectively. The difference between pre-test and post-test mean knowledge was significant indicated by $Z$ p value (0.016). 
Impact of Educational Intervention on Knowledge Regarding HIV/AIDS among Adults

\begin{tabular}{|c|c|c|c|c|c|}
\hline \multirow{2}{*}{ Meaning of HIV/AIDS } & \multicolumn{2}{|c|}{ Pre-test } & \multicolumn{2}{|c|}{ Post-test } & \multirow{2}{*}{$X$ Square $p$ value } \\
\hline & No. & $\%$ & No. & $\%$ & \\
\hline Sexually transmitted disease & 27 & 40.3 & \multirow{4}{*}{$\begin{array}{l}60 \\
35 \\
56 \\
15\end{array}$} & 89.5 & 0.000 \\
\hline Preventable disease & 6 & 8.9 & & 52.2 & 0.000 \\
\hline Blood born disease & 32 & 47.7 & & 83.6 & 0.000 \\
\hline Fatal disease & 23 & 34.3 & & 22.4 & 0.125 \\
\hline Mean Knowledge & \multirow{2}{*}{\multicolumn{2}{|c|}{$\begin{array}{l}1.3 \\
0.67\end{array}$}} & \multirow{2}{*}{\multicolumn{2}{|c|}{$\begin{array}{l}2.4 \\
0.50\end{array}$}} & \multirow{2}{*}{$0.016^{*}$} \\
\hline Standard deviation & & & & & \\
\hline
\end{tabular}

$\mathrm{n}=67,{ }^{*} \mathrm{Z}$ test

Total $55.2 \%$ and $14.9 \%$ respondents answered that sharing syringes and needles and sharing razors and blades transmit HIV/AIDS in the pre-test followed by 98.5\% in the post-test (Table 3). Similarly $35.8 \%$ and $14.9 \%$ respondents respond that HIV/AIDS transmit to baby during pregnancy and during breast feeding in the pre-test followed by $98.5 \%$ and $92.5 \%$ in the post-test. Similarly $38.8 \%-68.7 \%$ respondents were confused about different modes which do not transmit HIV/AIDS.
The mean scores on knowledge about the mode of transmission of HIV/AIDS as a whole in the pre-test and the post-test were found 6.37 and 13.92 with the standard deviations of 4.85 and 1.63 respectively. Further the difference in knowledge as a whole between pre-test and the post-test was found highly significant $(0.000)$.

Table 3. Respondents' Knowledge about Mode of Transmission of HIV/AIDS

\begin{tabular}{|c|c|c|c|c|c|}
\hline \multirow{2}{*}{ Mode of Transmission } & \multicolumn{2}{|c|}{ Pre-test } & \multicolumn{2}{|c|}{ Post-test } & \multirow{2}{*}{$X$ square $P$ Value } \\
\hline & No. & $\%$ & No. & $\%$ & \\
\hline Unprotected sex & 54 & 80.6 & 67 & 100 & 0.000 \\
\hline Unscreened blood transfusion & 34 & 50.7 & 66 & 98.5 & 0.000 \\
\hline Sharing syringes and needles & 37 & 55.2 & 66 & 98.5 & 0.000 \\
\hline Sharing razors and blades & 10 & 14.9 & 66 & 98.5 & 0.000 \\
\hline \multicolumn{6}{|l|}{ Mother to baby: } \\
\hline during pregnancy & 24 & 35.8 & 66 & 98.5 & 0.000 \\
\hline during breastfeeding & 10 & 14.9 & 62 & 92.5 & 0.000 \\
\hline Sharing meal * & 21 & 31.3 & 67 & 100 & 0.000 \\
\hline Kissing* & 30 & 44.8 & 67 & 100 & 0.000 \\
\hline Shearing toilet* & 32 & 47.8 & 66 & 98.5 & 0.000 \\
\hline Sharing the swimming pool* & 31 & 46.3 & 66 & 98.5 & 0.000 \\
\hline Insects / animals bite* & 33 & 49.3 & 66 & 98.5 & 0.000 \\
\hline Handshaking* & 43 & 64.2 & 65 & 97.0 & 0.000 \\
\hline Hugging* & 28 & 41.8 & 66 & 98.5 & 0.000 \\
\hline Sitting together & 29 & 43.3 & 66 & 98.5 & 0.000 \\
\hline Mean knowledge & \multicolumn{2}{|l|}{1.3} & \multicolumn{2}{|l|}{3.9} & \multirow{2}{*}{$0.000 \dagger$} \\
\hline Standard deviation & \multicolumn{2}{|l|}{0.68} & \multicolumn{2}{|l|}{1.0} & \\
\hline
\end{tabular}

$\mathrm{n}=67$, * Negative responses, $\dagger \mathrm{Z}$ test 
About $55.2 \%$ and $37.3 \%$ respondents answered about the abstain from sex work and use condom are the ways of prevention of HIV/AIDS transmission in the pre-test followed by $100 \%$ in the post-test (Table 4). Similarly, 47.8\% respondents argued to be faithful between partners in the pre-test followed by $97.0 \%$ in the posttest. In addition, $26.9 \%$ respondents answered that avoid transfusion of unscreened blood and its product and do not share syringes and needles are the ways to prevent from getting HIV/AIDS in the pre-test followed by 95.5 $\%$ in the post-test. More so, $8.9 \%$ respondents answered that if someone come in contact of blood it should be wash out immediately in the pre-test followed by $97.1 \%$ in the post-test.

Mean scores on knowledge about the ways to prevent transmission of HIV/AIDS as a whole in the pre test and the post test were found 1.94 and 4.88 with the standard deviation of 1.98 and 0.56 respectively. Further the difference in knowledge between the tests found highly significant $(\mathrm{P}<0.05)$.

Respondents mean knowledge about HIV/AIDS in general such as its meaning, high-risk groups, symptoms of AIDS, mode of transmission, preventive aspects, consequences and drug used for HIV / AIDS was increased significantly in the post-test (Table 5). Whereas, on the whole, mean knowledge about HIV/AIDS was 2.12 in the pre-test and 4.8 in the post-test with standard deviation 4.5 in the pre-test and 1.0 in the post-test. Further, the difference between pre-test and post-test was calculated by applying Chi square test where $p$ value was 0.001 at the 0.05 level of significance showed rejection of null hypothesis, and it is concluded that there is significant increase in the level of knowledge about HIV/AIDS in the post-test. Therefore educational intervention was effective to bring significance increase in the knowledge about HIV/AIDS, among the participants of the study.

\begin{tabular}{|c|c|c|c|c|c|}
\hline \multirow{2}{*}{ Preventive Measures } & \multicolumn{2}{|c|}{ Pre-test } & \multicolumn{2}{|c|}{ Post-test } & \multirow{2}{*}{$\mathrm{X}$ Square $\mathrm{P}$ Value } \\
\hline & No. & $\%$ & No. & $\%$ & \\
\hline Avoiding multiple sex partner & 37 & 55.2 & 67 & 100 & 0.000 \\
\hline Using condom & 25 & 37.3 & 67 & 100 & 0.000 \\
\hline Being faithful to partner & 32 & 47.8 & 65 & 97.0 & 0.000 \\
\hline Using only screened blood and its products & 18 & 26.9 & 64 & 95.5 & 0.000 \\
\hline Not sharing syringes and needles & 18 & 26.9 & 64 & 95.5 & 0.000 \\
\hline Immediately washing out the blood if get contact & 6 & 8.9 & 65 & 97.1 & 0.000 \\
\hline Mean Knowledge & \multicolumn{2}{|l|}{2.05} & \multicolumn{2}{|l|}{5.65} & \multirow{2}{*}{$0.000^{* *}$} \\
\hline Standard deviation & \multicolumn{2}{|l|}{2.02} & \multicolumn{2}{|l|}{0.76} & \\
\hline
\end{tabular}

Table 5. Respondents Knowledge about HIV/AIDS as a Whole

$(n=67)$

\begin{tabular}{|llllll|}
\hline \multirow{2}{*}{ Knowledge } & \multicolumn{3}{c}{ Pre-test } & \multicolumn{3}{c|}{ Post-test } & Z test P value \\
\hline Meaning of HIV/AIDS & SD & Mean & SD & \\
Symptoms of AIDS & 1.3 & 0.67 & 2.4 & 0.50 & 0.016 \\
Consequences & 1.3 & 0.68 & 3.9 & 1.0 & 0.000 \\
High risk groups & 1.6 & 1.35 & 3.4 & 0.67 & 0.000 \\
Mode of transmission & 1.9 & 1.13 & 3.2 & 1.22 & 0.000 \\
Prevention & 6.4 & 4.85 & 13.9 & 1.63 & 0.000 \\
Drug used for AIDS & 2.0 & 2.02 & 5.6 & 0.75 & 0.000 \\
Total mean score & 0.3 & 0.54 & 1.5 & 0.80 & 0.000 \\
\hline \hline
\end{tabular}


Impact of Educational Intervention on Knowledge Regarding HIV/AIDS among Adults

\section{DISCUSSION}

The study revealed that all of the respondents heard about HIV/AIDS, and mostly they acquire information from television and radio. The study highlighted that before intervention mean knowledge about HIV/AIDS was 1.3 which was changed to 2.4 later after intervention. However, a study done among adolescence showed that $84.0 \%$ respondents had knowledge about meaning of HIV/ AIDS. ${ }^{5}$ The study revealed that only $43.3 \%$ respondents had knowledge that carrier stage of HIV virus is life long and more than $85 \%$ respondents knew about it after intervention. The study also presented that respondents' knowledge about mode of transmission was ranged from $14.9 \%$ to $80.6 \%$ in the pre-test and $92.5 \%$ to $100 \%$ in the post-test followed by mean score of 6.37 in the pre-test and 13.92 in the post-test. However the study carried out among adolescence revealed that knowledge about different mode of transmission was ranged from $91.4 \%$ to $77.7 \% .{ }^{5}$ Before intervention only $49.2 \%$ respondents' had knowledge that HIV virus weakens immunity power, where after intervention, $89.5 \%$ knew about weakened immunity. The important aspect of HIV/AIDS is carrier state, which was known by $43.3 \%$ in the pre-test and by $85.1 \%$ in the post test.

The findings of the study showed that education intervention played an important role in increasing knowledge about HIV/AIDS which can be supported by the study "Evaluation of a School Based HIV/AIDS Educational Intervention in Ukraine". ${ }^{6}$ Regarding the mode of transmission, $80.6 \%$ respondents had knowledge that HIV/AIDS get transmitted through sexual contact, $55.2 \%$ had knowledge about sharing injections. Only $14.9 \%$ to $35.8 \%$ had knowledge that HIV/AIDS get transmitted from infected mother to baby during breastfeeding and during pregnancy in the pre-test, and in the post-test, more than $98.5 \%$ respondents had knowledge about different modes of transmission and $92.5 \%$ had knowledge about the mother to child transmission of HIV/AIDS. Findings of the study revealed that most of the respondents had misconception about the mode of not transmission of HIV/AIDS such as mosquito/ insects bites, kissing, hugging, and sharing toilet, food and handshaking. This finding was supported by the study among street children of Kathmandu valley. ${ }^{7}$ After intervention $92 \%$ had knowledge about transmission through sexual contact and $76 \%$ knew that mosquito bites doesn't transmit HIV/AIDS. Before intervention, mean knowledge for ways to prevent transmission of HIV/AIDS was 2.05 which were increased to 5.65 after intervention.
Most of the respondents of this study were female, only literate and only $23.9 \%$ had taken training about HIV/AIDS, which might be the reasons behind relatively limited knowledge of the respondents about HIV/AIDS before education intervention and after intervention there was a significant increase in respondents' knowledge. The study findings indicated that there was significant increase in the knowledge in all the aspects of HIV/AIDS after education intervention. All of the respondents indicated that there is a need of awareness program about HIV/AIDS

\section{CONCLUSION}

From the above discussion it can be concluded that education played an important role in increasing knowledge of the respondents about HIV/AIDS. If they are aware about different mode of transmission and preventive aspects of HIV/AIDS, their chance of involvement in risk behavior might be reduced.

\section{ACKNOWLEDGEMENT}

I would like to express my sincere gratitude to my academic advisor Ms. Ganga Chitraka Associate Professor of Maharajgunj Nursing Campus for continuous guidance and support through out the research period, the Chairperson of Research Committee Professor Dr. Indira Singh, and all the members of research Committee.

\section{REFERENCES}

1. UNAIDS. UNAIDS confirms support for needle exchange. Kathmandu: UNAIDS; 2006.

2. SAARCTuberculosis Centre. HIV and AIDS in the SAARC Region, An Update 2005. Kathmandu: SAARC Tuberculosis centre; 2005.

3. Piot P, Bartos M, Ghys PD, Walker N, Schwartländer B. The global impact of HIV/AIDS. Nature. 2001 Apr 19;410(6831):968-73.

4. Ministry of Health, National Centre for AIDS and STD Control Nepal. National HIV / AIDS Strategy (2002-2006). Nepal: Ministry of Health; 2003.

5. Singh S K, Manandhar N, Prasai M, Patowary S, Krishna G. An Awareness Study of HIV/AIDS among Adolescent Students of Chitwan District, Nepal. Journal of Institute of Medicine 2005;27(3):17-20.

6. Kyrychenko P, Kohler C, Sathiakumar N. Evaluation of a schoolbased HIV/AIDS educational intervention in Ukraine. J Adolesc Health. 2006 Dec;39(6):900-7. Epub 2006 Aug 30.

7. Gurung G. Knowledge and attitude on HIV/AIDS and sexual behavior of street teenagers in Kathmandu valley. JNHRC 2004; 2(2):22-9. 